\title{
Traffic Woes, Metro Manila, and Collaborative Problem-Solving: A Case Study of Computer-Mediated, Peer-Produced Information Infrastructure in the Field of Transportation in the Philippines
}

\author{
Joshua Ramon Enslin'1
}

\begin{abstract}
The chaotic traffic situation in Metro Manila has been characterized as a major roadblock to the country's economic development and has turned into an important discussion point in political debates. In this paper three traffic related web services, aimed at helping their users gain an insight into the traffic situation of Metro Manila and beyond are analyzed in regards to their use of cooperation using Benkler's concept of Collaborative Peer Production. The three web services differ starkly from each other in their concept - PH-Commute.com is a blog, Taxikick.com is a service for short messages pertaining to misbehaviors of taxi drivers, Sakay.ph is a navigation service. As I conclude, all three however share in common that they are indeed highly dependent on cooperation on different layers. Determined by the underlying concept of each of the websites, they incorporate inputs from their users, but they might also let their users help them in developing their software by publishing their source code, and they rely on community-created, open-source software infrastructure to be able to run their own.
\end{abstract}

Keywords: Infrastructure, Traffic, Metro Manila, The Philippines, Collaborative Peer Production

\footnotetext{
${ }^{1}$ M.A. student of Southeast Asian Studies currently enrolled at Goethe University Frankfurt. His main research interest concern contemporary labor migration and the history of ideas in Indonesia and the Philippines. He has previously worked as a translator from Indonesian to German and as a software developer. Corresponding e-mail: Joshua.enslin@yahoo.com
} 


\section{Introduction: Discussing the Web}

Along with invention of the World Wide Web (WWW) came promises of freedom of expression, collaboration, and - most importantly for this paper decentralization and development. Proponents of these ideals envisaged a world in which information could be created by anyone and consumed by everybody else, shared from peer to peer, instead of having to be channeled through mass media to reach larger audiences. With the rise of the second generation of open-source software, most significantly the operating system Linux, a similar pattern was envisaged and apparently described for this (Raymond, 1997). At least since this shift from a discussion focused on information production in mostly political terms to a broader discussion reaching from political and social implications economic ones.

Criticisms of the initial optimism soon arose. It was argued that a totally leveled field in information would lead to chaos, that audiences could not differentiate between relevant, irrelevant or even outright false information. On the other hand, critics argued that human nature in general made an effective and truly collaborative system impossible. To use Benkler's (2011) terms, they invoked the need for 'leviathan' (a strong government) and the 'invisible hand' (of the market), to counter notions of the 'penguin', productive collaboration of people. ${ }^{2}$

While the first generation of praises on the Internet could clearly be shown to be naive and overly simplistic, a new generation of more optimistic literature on the effect of the Internet on society arose. This newer school of optimists uses strong evidence from studies from a wide array of scientific fields to underline the possibility of a society-based collaboration and mutual aid and solidarity, enabled by the potentials modern information and communication technologies (ICTs) hold for decentralization and non-proprietary production (Benkler, 2006; Benkler \& Niessenbaum, 2006; Shirky, 2008; Shirky, 2011).

While generally optimistic, this school of thought acknowledges certain restrictions and characteristics of these less hierarchical forms of social organization. First, contributors to a community-based project are not paid. This means that the

\footnotetext{
${ }^{2}$ In choosing the image of the 'Penguin ', which he juxtaposes to government control (as symbolized by Hobbes' Leviathan) and the free market (Smith's invisible hand), Benkler makes reference to Tux, the mascot of Linux, to put a symbol to collaborative peer production.
} 
tasks a contributor can take over at one point in time need to be kept relatively small and easily manageable, 'fine-grained' (Benkler, 2006). Second, they rely on a much larger and diverse group of contributors than traditional enterprises. This diverse group of contributors is unlikely to share the same motivation (Benkler \& Niessenbaum, 2006). Third, the relationships between individuals collaborating on a project are much commonly weaker than in traditional teams. Finally, legal boundaries and institutionalization can strongly hamper their success.

The term project is used in a very wide definition here. It may be a common project in the literal sense (like the creation of a collaboratively produced online encyclopedia), or a common endeavor in the sense of a still more decentralized community of practice (for example the "blogosphere"). In fact, Benkler argues:

However, if we were to step back and look at the entire phenomenon of Webbased publication from a bird's-eye view, we would see that the architecture of the World Wide Web, in particular the persistence of personal Web pages and blogs and their self-contained, technical independence of each other, give the Web as a whole the characteristics of modularity and variable but fine-grained granularity (2006, p. 102).

This more differentiated approach to the potentials of the WWW, the Internet, and many modern ICTs in general has been long-standing and has led to a large body of literature, reaching into many fields of computer-mediated communication (Ratti, 2013; Fabbretti, 2014).

Given the chances the original thinkers of the new school of thought on the Internet described above have attributed to collaborative methods in advancing the economies of countries in the Third World ${ }^{3}$, it is surprising that there is still comparatively little literature relating this school of thought with developments in Southeast Asia. In this paper I aim to do so.

I discuss three web-based services from the Philippines, working to provide information on transportation infrastructure. After my initial introduction to the discourse regarding the Internet and society, it is necessary to situate the three services in the contexts provided in the title: first, the Internet in the Philippines; second the situation of transportation infrastructure in the Philippines. These

${ }^{3}$ I consciously use the term Third World here, as I argue that a) the legacy of the Cold War - in which the term was created - is still of utmost importance in many of the countries. Just as other terms, created to replace this term (e.g. Global South), it has intended to give a common identity among countries from these countries, and should thus, I argue, not be dismissed for supposedly negative connotations. 
descriptions constitute the first part of my paper. In the second part of the paper, I turn to case studies of the three websites, taxikick.com, sakay.ph and phcommute.com. I start with introducing the websites based primarily on their selfdescriptions. I then focus on technical aspects of the websites, to put them into context with discussions on the Internet at large as outlined above. Finally, I discuss the contents posted on the websites.

\section{The Philippines, Filipinos, and the Internet}

Given its status as a developing country, the Philippines have a strong Internet distribution. The World Bank estimates about 39.7 per cent Internet users among Filipinos. This number surpasses the estimate for Thailand, which stands at 34.9 per cent for the time from 2011 to 2015 (World Bank Indicators). Globe Telecommunications, one of the main telecommunications providers in the country, states that there are "119 Million Mobile Phone Subscriptions (117\% penetration rate) (Rappler.com N/A), out of which a large majority have mobile Internet access. Given these numbers and the fact, that wide-spread use of technological devices by more than one person, for example in the form of a 'family computer', is common, makes it likely that the World Bank's numbers are a rather conservative estimation.

The Internet has led both to economic as well as social transformations in the Philippines. On the economic side, the rise of a call center industry can be observed in the Philippines. High levels of education and English language proficiency among Filipinos, combined with relatively low wages and labor protection standards, have made the country attractive for this industry.

More significant for my paper are the social effects, which further underline the importance the Internet has gained in Filipino society. Three factors must be underlined in this regard: the high number of Filipinos working abroad as so-called OFs (Overseas Filipinos), the extreme popularity of social media ${ }^{4}$, most importantly Facebook, and the development of Internet-based groups of interest with a clearly Filipino identification.

\footnotetext{
${ }^{4}$ I italicize the term social media here to emphasize its contested definition. Arguably, email or even the telephone (when using conference calls) were earlier forms of social media. Alternative, popularly used terms like social networks are certainly even less apt to use.
} 


\section{OFs and Their Kin: Keeping in Touch Using the Internet}

According to estimates by the Commission on Filipinos Overseas (2014), over 10 per cent of the Filipino population are overseas, splattered across over 221 countries and autonomous regions all over the world. While a considerable group has settled down in their host countries, especially Filipino Americans, the majority is working abroad to remit large an often large part of their income for their families' livelihood and improved living standard (Aguilar et al., 2009; Parreñas, 2001). ${ }^{5}$

Both "settled" OFs and OFWs (Overseas Filipino Workers; previously called Overseas Contract Workers to emphasize their only temporary migration) have been found to keep ties to the Philippines (Aguilar, 2014; Parreñas, 2001) through the use of any communication technology available at a time (Aguilar et al., 2009; Fajardo, 2011).

The large majority of research on Filipino migration focuses on disenfranchised groups of migrants. This, combined with the general slow speed of the peer-review process, has led to a situation where migrants are still described as using 'snail mail', telephone calls and sometimes text messages as their primary means of communication 'home' (Aguilar et al,. 2009; Parreñas, 2001a; Parreñas, 2005; Parreñas, 2005a). While research on their use of the Internet is only slowly emerging (Aguila, 2015), it is safe to assume that the many of the characteristics of their use of other, equivalent, means of telecommunication apply also for their use of the Internet.

A most important concept and motivation in regard of the use of telecommunications by OFWs especially is what Parreñas (2001) aptly termed "transnational mothering," the attempt by parents - especially mothers - working overseas to 'keep in touch' with their children and remain acknowledged as parents despite being 'away from home'. To do so, they regularly call their families and ask let their children detail their lives. They might also ask their families to turn on the speaker function and let them listen to the sounds of the everyday life of their families (Aguilar et al., 2009, pp. 254-271). Notably, these findings still describe telephone communication, which generated heavy financial costs for the research

\footnotetext{
5 The term OFs is the broadest common term describing Filipinos who have migrated abroad. As I point out below, a distinction between "settled" OFs with a citizenship that is not Philippine and OFWs, who work abroad but plan to return eventually, would be wrong for the purposes of this paper. For definition of the terms see: Asis \& Roma, 2009; Aguilar, 2014; Campomanes, 2003.
} 
subjects. Given the availability of free-of-charge alternatives using the Internet, it is likely that this behavior is at least transferred to the use of new technologies, if not even further amplified by these. This example may give a hint at the importance the modern ICTs have on the workings of interpersonal and even familial relationships for many Filipinos (Pertierra, 2013). ${ }^{6}$

Second, and more specific for use of the Internet, Filipinos Overseas have been found to create forums of communication to mutually reaffirm their identity as fellow Filipinos. These forums may take the form of websites and Facebook 'fan pages' (Del Mundo Duaqui, 2014), or listservs (Ignacio, 2000) and Facebook 'groups'. Besides being important expressions of identity seeking and (re-)framing, these forums also provide valuable information for the daily lives of Filipino communities abroad. It is important to note that OFs often come from middle class families, and have a good command of English. While more informal groups (like listservs) may use Tagalog/Filipino ${ }^{7}$ or 'Taglish' as a primary language, their more formal media outlets on the Internet primarily use English.

\section{Social Media and the Philippines}

The Philippines have been repeatedly referred to as having one of the most active communities on Facebook; reportedly, there are 47 million Facebook accounts created in the Philippines (Rappler.com N/A). Besides very actively sharing their personal lives on Facebook, Filipinos discuss a wide array of topics on it. It has been argued, that important political events such as the passing of the RH Bill or the rise of president Rodrigo Duterte would not have been possible without their supporters gathering in strong groups on social media.

Given the large number of accounts and Facebook's recent opening of its Internet.org project, which aims to make strongly restricted but free-of-charge Internet access available to the people, it can be assumed that the users of especially

\footnotetext{
${ }^{6}$ Another notable hint at the high adoption rates of free-of-charge telecommunication services like Skype and Viber among OFs may be that entertainment shows have begun to build them into their concepts. For example, one of the more popular web shows of the country, Good Times with Mo, lets listeners use these services to call-in. This option is frequently used by OFs.

${ }^{7}$ The naming of the national language of the Philippines remains a debated issue in the Philippines. While the Commission on the Filipino Language defines the Filipino language as a new language based on Tagalog but using a large number of loan words (Virgilio S. Almario, Pers. Comm., Oct. 2014), Tagalog is the more commonly used name to refer to the national language. C.f. Gonzalez 1980.
} 
Facebook have a comparatively diverse background. Both Tagalog/Filipino and English are frequently used on it.

\section{Filipino-Identified Groups of Interest}

A final important development is the development of groups of interest on the Internet. While this is a development of world-wide significance (see e.g.: Thorne et al., 2009), Filipinos have notably developed such groups with a strong Filipino identification. I will briefly outline the results of a discussion the New Worlds Alliance, a fan community with strong Filipino identification, that writes fan fiction on popular literature by Santos (2013).

Important for my later discussion of taxikick.com, sakay.ph ph-commute.com are Santos' findings that the group organizes both online and offline, with their initial meeting point being online, that they are focused on Metro Manila, proficient in English, and a middle class background.

\section{Transportation Infrastructure in the Philippines}

Transportation infrastructure in the Philippines is a regularly debated topic in political discussions (Salaverria, 2016). Especially the National Capital Region (NCR) has made headlines for its traffic problems, and has led to considerable financial damages (Santiago, 2016). I will restrict my description on the NCR here, as it is by far most relevant to the services to be discussed.

First of all, it needs to be pointed out that the means of transportation available in the NCR are extremely diverse. Public mass transport is facilitated primarily through inner-city train lines (the LRT and MRT systems), buses and jeepneys. ${ }^{8}$ While the train lines are operated by companies at least partially owned by the government, there is a large number of bus operators. Jeepneys have a still more decentralized ownership structure. Many are owned by families, which own only one.

Individual transportation on the other hand is facilitated through cars and motorcycles, whose numbers have seen a steep increase over the last years (Department of Transportation and Communications, 2015), and unmotorized means of transportation such as tricycles. Taxis are made available by different

\footnotetext{
${ }^{8}$ Other means of public transportation include for example ferries, but their usage is still very limited.
} 
operators, but they are mostly considered to be unsafe. Especially the rise in individual transportation has led to extreme levels of congestions on the main roads (Santiago, 2016). While a reduction of the number of cars and a further strengthening of the train systems are the most commonly proposed solutions, part of it will certainly need to be an organized information infrastructure to let potential passengers use the available public transportation options efficiently. This is however often hard to achieve, given the decentralized nature of much of Manila's public transportation infrastructure.

Different sources, most prominently the MMDA (Metro Manila Development Authority) and the DOTC (Department of Transportation and Communications), are collecting data on the traffic situation around the NCR. Their datasets are however often incomplete or only deal with a limited set vehicle types. A first problem of data collection on traffic and transportation in the NCR can thus be identified to be the plain mass of data to collect and the unification of different data sets.

The collectors' data is then made openly accessible to the public. This may take the form of statistics released in as PDFs or in machine-readable tables. While data thus released may be of use to researchers and programmers, organization and presentation of the data are a second problem, if one is to make the data readily accessible to commuters. Using different approaches and different levels of collaboration with government agencies and operators, the three services I discuss in the following part of my paper try to bring information on transportation in Metro Manila to their users.

\section{Taxikick.com, ph-commute.com, and sakay.ph}

In this part of my paper I discuss the services taxikick.com, ph-commute.com, and sakay.ph as contributions to the creation of a usable information infrastructure with the aim of alleviating the problems commuters and travelers in the NCR have with its transportation system. I analyze them in the context of collaboration on the Internet, as outlined in the introduction of this paper.

As the three services use very different approaches, it is important to recall the earlier definition of 'project'. One of the projects (taxikick.com) relies mainly on user input, ph-commute on the other hand is a blog relying mostly on self-gathered 
information from its authors. I argue, however, that both can and should be analyzed in the context of collaboration on differing levels.

First of all, all three projects work based on the Internet. The Internet is marked by a decentralization infrastructure based on collaboration both in terms of available contents and tools, as pointed out by Benkler (2006). Relying on open standards and protocols like the Hypertext Transfer Protocol (HTTP) and free or free-of-charge programming languages and tools to different extends means that they are naturally part of a large scale collaborative system, the Internet.

Second, all the services to be analyzed are linked by their common aim of providing information on the topic of transportation in Metro Manila. This means, that they can be seen as contributions to a common project. Finally, especially sakay.ph and taxikick.com can be seen as a collaborative projects themselves, as they rely (among others) on user inputs. Ph-commute.com has also made some efforts to create an online community.

After an introduction of each of the services, I will begin my analysis with a technical discussion of the three services. Based on the available code I aim to outline in how far their development depended on previous efforts. Especially in light of the debate on 'electronic' and more recently 'digital colonialism', I distinguish between paid, free-of-charge, and open source code used in building the services. While access to paid solutions is generally restricted by the more limited financial strength of nongovernmental actors in the Philippines (as compared to the first world), free-ofcharge but closed source solutions are more easily available. Their usefulness is however often limited by their original context building, which, to use Tedre et al.,'s phrase, carries a "Western bias" (2006, p. 129). Open source solutions - due to their open and collaborative environments - however are readily accessible to the creators of services such as those analyzed and may be adjusted to fit the need of their new context of use.

In the final subsection of this part of my paper I discuss how users are or have been engaged by the services. 


\section{Introduction of the Services}

In this subsection, I present a brief description of taxikick.com, phcommute.com, and sakay.ph9, based on a review of their websites, their selfdescription and help pages, and media reports.

Motivated by the widespread violation of transportation and traffic regulations among taxi drivers, taxikick.com is a service that aims to collect data on these violations and facilitate easier communication between passengers observing such violations and the respective government agency, the Land Transportation Franchising and Regulatory Board (LTFRB). It also shares its data with companies and operators working with taxis. It was founded by "[t]wo college friends" (Taxikick.com N/A), in late 2011 (Magdirila, 2013).

Taxikick.com is completely WWW-based and features a simple page design. Users can search for violations based on the collected data. Below the search function, the most recent reports are displayed. Each is clickable, to reach a linkable page containing only the respective entry. Finally, a commenting tool is embedded below the pages. Advertisements are embedded to finance the service.

$\mathrm{Ph}$-commute is a blog, in which the authors note down ways they travelled. Judging from posts on its social media pages and the timestamps of posts, the project has been largely abandoned since 2011 . The earliest posts were written in 2008, and it was founded by two computer science graduates. Just like taxikick.com, it embeds advertisements on its website.

Sakay.ph is a service available both on the WWW and as an app. It incorporates data from the above-mentioned government agencies with data submitted by independent developers and users. Another source of data is data collected from students riding along and measuring different routes within the city (Mikulski, 2014). Using these various sources of data, sakay.ph offers a route planner that - as opposed to larger scale solutions like Google Maps, which it partially embeds into its service - also displays information on only locally available means of transportation like jeepneys. This project, like the others I introduced above, was founded by a team of team of two developers. It has since become one of the projects of a team of open source developers, which now also releases the source code of sakay.ph openly.

\footnotetext{
${ }^{9}$ A very helpful source of information on sakay.ph is also the blog of one of its programmers (Dy 2013-2015).
} 


\section{Technology and Collaboration in the Projects}

All of the portrayed projects make extensive use of preexisting software as building blocks of their infrastructure or, indeed, as their infrastructure. As modern day programming is based on the use of different modules or building blocks, this is the largest and most basic layer of collaboration. Different modules created collaboratively by peers or in more hierarchical structures are combined to create a new product. Only the collective effort of the different projects involved in building the basis for a service make the functioning of the service possible.

$\mathrm{Ph}$-commute is an example of the latter alternative: it is using Google's Blogger.com platform for hosting and organizing its data. For monetarization, it uses Google's advertisements services. It thus runs entirely on proprietary and closed source software, that is easy to utilize and fits the purpose of a simple blog.

Given the concept of ph-commute as a blog, in which it is sufficient for the authors to share their information in an ordered manner and only minor configurations had to be made in the settings of the used software. While the closed source nature of the blogging engine does not permit adjustments, these seem to not have been necessary.

Contrastingly, both sakay.ph and taxikick combine open source and closed software in them. Sakay.ph is the most complex of the three services discussed and its own code is released as open source. Except for the display of Google Maps, it is entirely based on free and open source software, ranging from the Open Trip Planner application programming interface (API) used to compute the best routes to design. ${ }^{10}$ The website nevertheless uses proprietary standards to ease linking at major social media services. Google Maps is embedded as a map service to display the available routes instead of free and open alternatives like Open Street Maps, assumingly because potential users are more used to the design of Google Maps and there is less confusion.

Taxikick.com goes further in combining or embedding proprietary and closed source services and software than sakay.ph. While the code it runs on is not openly accessible, it reportedly runs on Ruby and MySQL, both of which are free-of-charge and open source (Edquilang, 2012). According to the same source, it originally used

\footnotetext{
${ }^{10} \mathrm{~A}$ non-extensive list of the used software can be found at http://sakay.ph/humans.txt, accessed 12 May 2016.
} 
the free and open source bootstrap framework for its design; it has since switched to a simpler and also free normalize.css. Taxikick.com embeds two external and proprietary services into its service. First, it uses Google's advertising services for monetarization. It is the only service among those I analyze in this paper to offer a commenting function. To do so, it embeds the service Disqus.

Based on these observations, I conclude that the choice of the creators to use collaboratively produced, free and open source software strongly depended on their services concept, the general popularity and availability of the potential software basis to be used, and the functions the software is used for in the project. Concept or motivation in this case refers to the complexity of the projects. Whereas the blogging concept as employed by ph-commute.com is comparatively general that does not demand much localization, a route mapping service like sakay.ph is a highly complex project, in which data from different sources needs to be automatically meshed. This means that the creators of sakay.ph needed a higher level of control over the technology used in their system - which makes open source, say, adjustable, solutions preferable. The creation of ph-commute.com did not require such a level of technical control over their platform.

Popularity and availability refers to, e.g., the way Google Maps is embedded in the sakay.ph as opposed to free alternatives of comparable quality. Finally, taxikick.com is a curious example of a strong combination of both ways. It is notable, that the key parts of the website are self-coded, using an open source basis. On the other part, useful but more marginal parts like the commenting function could be 'outsourced' to external, proprietary services.

\section{Engagement and Collaboration on the Services}

In this subsection, I discuss how inputs by different sources and collaboration are used in the building of the services. A comparison is again fruitful, as the different aims and concepts of the services demand different levels of user engagement. Again, given its nature as a blog, ph-commute is least based on user inputs and collaboration in the aggregation of its data among the services discussed here. As previous research on the 'blogosphere' has however shown, bloggers oftentimes share information gathered through various communication channels, e.g. the comments section on their websites or email (Benkler, 2006, pp. 212-272). 
Confirming this finding, ph-commute.com features a section "Questions from Real Commuters Answered!", in which the bloggers collect user questions and their answers to these. This section covers roughly two years of question and answers, or about 750 entries.

This section of user inputs is also marked by a relative openness in regards to language. While the other sections of the blog are consistently written in English, user questions were increasingly written in Tagalog/Filipino. As pointed out above, the English language is used as a marker of social class among Filipinos. The increasing number of Tagalog/Filipino language questions may thus hint to an increasingly higher level of diversity in regards to social status among its users. Answers however are written in English, even if the question was posted in Tagalog/Filipino.

Sakay.ph combines collaboration by users on different levels with data inputs taken from governments agencies. Collaboration by users can take place both in contributing to the source code and to the datasets the service uses. In both cases the user needs to join the service Github, and look at the raw data. Thus, entry hurdles for contributions are comparatively high. On the other hand, sakay.ph is completely available in both Tagalog and English, and thus more accessible to the less well-off.

Another major source used by sakay.ph are government agencies, that openly publish their data. Sakay.ph thus combines both fine-grained inputs by individuals and larger inputs by government agencies. While the service could theoretically be run without the individuals' inputs, they supplement the government data and can serve to make it more accurate. Given the chaotic traffic situation, high levels of congestion, and only incomplete mapping of certain areas of the NCR, this can be a considerable improvement.

Contrary to ph-commute.com and sakay.ph, the data on taxikick.com is completely generated by the services' individual users. Users enter the taxi's details, like plate number and location, and basic contact information ${ }^{11}$ and a comment and send it to the service, which then publishes it and sends it to the LTFRB. Given the availability and general small size of the data set a user needs to input to "kick a taxi", this can be described as an extremely fine-grained input.

\footnotetext{
${ }^{11} \mathrm{~A}$ valid email address is required to use the service.
} 
On the other hand, each post features a 'comments'. This feature allows for different ways of use: Some users may only write a short line reporting the respective incident, other might write their posts in letter form, directly addressing the community and with long descriptions. By not defining this part of the input form too closely, taxikick.com thus enables users to decide on their own how detailed their contribution will be.

The embedded comments section below each page on taxikick.com is similarly open to creative use. Users for example use it to comment on search pages for not yet added license plates (thus effectively pointing out an offense without using the actual form for doing so) or to offer additional information on a taxi driver.

Both the posts' comments part and the comments below each post are open to both English and Tagalog. Especially in the case of the latter, Tagalog is frequently used. The service itself, sans user-generated content, is consistently kept in English and has no option to switch between languages. ${ }^{12}$

Finally, all three services offer social media pages, on which they share news about the development of their software (sakay.ph), re-post their contents (taxikick.com) and traffic related news (ph-commute). They thus employ social media in different ways to either create and further engage their community and/or to increase the outreach of their services.13

\section{Final Remarks}

In this paper I have discussed three traffic-related Filipino web services in light of the concept of collaboration. All three can be seen as collaborations to a larger project themselves - easing the traffic woes of the NCR and the Philippines at large. They incorporate tools and products, often created in a collaborative process, to work together with own code to create their services. Finally, they engage their users and use data provided by these to improve their services. In doing so, they confirm Benkler's proclamation, that 'peer-produced' information production needs to be split into relatively fine-grained tasks.

\footnotetext{
${ }^{12}$ As the 'target audience' of taxikick.com are people using taxis, who tend to have more money at their disposal and can thus also afford a higher education in a country with a strongly privatized education system (Raffin \& Cornelio, 2009), this is not surprising.

${ }^{13} \mathrm{~A}$ more in-depth analysis of the use of social media by Filipino web projects would hold enough content for an own paper and will thus not be undertaken here for a lack of space.
} 
The three services I discussed not only outline different approaches to collaboration, but especially ph-commute.com and sakay.ph can be seen as different steps in reaching a rather similar aim: both aim to provide routing information. $\mathrm{Ph}$ commute.com was founded five years before sakay.ph, and is marked by offering much fewer opportunities for user engagement and no automated organization of its data. It featured stronger restrictions in terms of language, say, social class of its users, than sakay.ph. Sakay.ph is also an example of how open government data which was not yet available at the most active times of ph-commute - can advance information infrastructure, which can in turn help people find solutions to their problems, e.g. the route to a place in a metropolis.

Taxikick.com on the other hand is an example of how giving users the opportunity to creatively use a service can lead to widely differing inputs and creative use. Differences in contents (e.g. in terms of details provided) as well as language and register occur. These become aggravated by the different situations users post their contents in ('comment' part of a post as compared to comments section below the post). By making users provide contact information with a valid email address for contact the service can nevertheless uphold a continuing cooperation with government agencies.

The three services discussed throughout this paper differ strongly in terms of the methods for user engagement used, their technological sophistication etc. Each, however, can serve as an example for a successful service in improving the traffic situation in Metro Manila. This shows the diversity of ways in which peer-production can be employed to solve or at least lessen social and economical problems. Although ph-commute and taxikick.com are not free of commercial interests, partial or complete integration of user inputs serves as an inexpensive possibility to improve the service. At the same time, the examples presented in this paper once again showcase the importance of fine-grained inputs in peer-production contents.

\section{References}

Aguila, A. N. (2015). The Filipino, Diaspora and a Continuing Quest for Identity. Social Science Diliman, 11(2), 56-89.

Aguilar, F. V. (2014). Migration Revolution: Philippine Nationhood and Class Relations in a Globalized Age. Quezon City: Ateneo de Manila University Press. 
Aguilar, F. V., et al. (2009). Maalwang Buhay: Family, Overseas Migration, and Cultures of Relatedness in Barangay Paraiso. Quezon City: Ateneo de Manila University Press.

Asis, M. M. B., \& Roma, G. A Guide to Key Concepts, Terms, Institutions and Policies on International Migration (With Special Focus on the Philippine Context). Quezon City: Scalabrini Migration Center.

Benkler, Y. (2011). The Penguin and the Leviathan: How Cooperation Triumphs over Self-Interest. Crown Business.

(2006). The Wealth of Networks: How Social Production Transforms Markets and Freedom. New Haven, Conn.: Yale University Press.

Benkler, Y., \& Nissenbaum, H. (2006). Commons-Based Peer Production and Virtue. Journal of Political Philosophy 14(4): 394-419.

Campomanes, O.V. (2003). The Vernacular/Local, the Nation, and the Global in Filipino Studies. Kritika Kultura 3: 5-16. Retrieved from http://kritikakultura.ateneo.net/images/pdf/kk3/vernacular.pdf.

Commission on Filipinos Overseas. (2014). Stock Estimate of Overseas Filipinos as of Dec. 2013. Retrieved from http://cfo.gov.ph/images/Statistics/STOCK_ESTIMATE/2013-Stock-

Estimate.xlsx (10 May 2016).

Del Mundo Duaqui, Y. (2014). Success Portrayal of Filipina Migrants in a Filipino Newspaper in Japan. In Lydia N. Yu Jose and Johanna O. Zulueta, eds. Japan: Migration and a Multicultural Society. Quezon City: Japanese Studies Program, Ateneo de Manila University.

Department of Transportation and Communication. (2015). Annual Report 2014. Retrieved from http://www.lto.gov.ph/component/jdownloads/send/7statistical-reports/276-annual-report-2014 (10 May 2016).

Dy,T. (2013-2015). Pleasant Programmer. Retrieved from http://pleasantprogrammer.com/ (13 March 2016).

Edquilang, R. 2012. How a New Mobile Web App Lets Filipinos Report Bad Taxi Drivers. Retrieved from https://www.techinasia.com/how-a-new-mobile-web-app-letsfilipinos-report-bad-taxi-drivers (13 May 2016).

Fabbretti, M. (2014). A Study of Contemporary Manga Scanlation into English. Unpublished PhD. Thesis. Cardiff School of Modern Languages. 
Fajardo, K. B. (2011). Filipino Crosscurrents: Oceanographies of Seafaring, Masculinities, and Globalization. University of Minnesota Press/University of the Philippines Press.

Gonzalez, A. B. (1980). Language and Nationalism: The Philippine Experience Thus Far. Manila: Ateneo de Manila University Press.

Ignacio, E. N. (2000). Ain't I a Filipino (Woman)? An Analysis of Authorship/Authority through the Construction of 'Filipina' on the Net. The Sociological Quarterly, 41(4), 551-572.

Magdirila, P. (2013). Rude Taxi Drivers, Beware: GrabTaxi and TaxiKick Sharing Passenger Feedback Data. Tech in Asia, 10 September 2013. Retrieved from https://www.techinasia.com/rude-taxi-drivers-beware-grabtaxi-taxikicksharing-passenger-feedback-data (11 March 2016).

Mikulski, J. 2014. The New Cartographers. Next City, 13 October 2014. Retrieved from https://nextcity.org/features/view/the-new-cartographers (12 May 2016).

Parreñas, R. S. (2005). Children of Global Migration: Transnational Families and Gendered Woes. Stanford, CA/Quezon City: Stanford University Press/Ateneo de Manila University Press.

. (2005a). Long Distance Intimacy: Class, Gender and Intergenerational Relations Between Mothers and Children in Filipino Transnational Families. Global Networks, 5(4), 317-336.

. (2001). Servants of Globalization: Women, Migration and Domestic Work.

Stanford, CA/Quezon City: Stanford University Press/Ateneo de Manila University Press.

. (2001a). Mothering from a Distance: Emotions, Gender, and Intergenerational Relations in Filipino Transnational Families. Feminist Studies, 27(2), 361-390.

Pertierra, R. (2013). We Reveal Ourselves to Ourselves: The New Communication Media in the Philippines. Social Science Diliman, 9(1), 19-38.

Raffin, A., \& Cornelio, J. S. (2009). The Catholic Church and Education as Sources of Institutional Panic in the Philippines. Asian Journal of Social Science, 37(5), 778-798. 
Rappler.com. (n.d.). A Profile of Internet Users in the Philippines. Retrieved from http://www.rappler.com/brandrap/profile-internet-users-ph (10 May 2016).

Ratti, S. (2013). Scanlators as Producers-An Illegal, Non-Profit, Fan Produced Alternative to Industrial Modes of Manga Localization. Unpublished MA. Thesis. Uppsala University.

Raymond, E. S. (1997). The Cathedral and the Bazaar. Retrieved from http://www.catb.org/ esr/writings/cathedral-bazaar/cathedral-bazaar/ (05 May 2016).

Reese, N., \& Soco-Carreon, J. (2013). No Call for Action? Why There Is No Union (Yet) in Philippine Call Centers? ASEAS - Österreichische Zeitschrift für Südostasienwissenschaften, 6(1), 140-159.

Reese, N. (2008). We are Living in a Different Time Zone': Transnational Working Places and the Concept of a 'Glocalized Intermediary Class. ASEAS Österreichische Zeitschrift für Südostasienwissenschaften, 1(2), 34-58

Salaverria, L. B. (2016). Poe: Too Many Lawyers for MRT Broth. Philippine Daily Inquirer, $29 \quad$ January $2016 . \quad$ Retrieved from http://newsinfo.inquirer.net/759794/poe-too-many-lawyers-for-mrt-broth (10 May 2016).

Santiago, R. S. (2016). Easing Metro Manila traffic congestion. Philippine Daily Inquirer, $\quad 10 \quad$ January $2016 . \quad$ Retrieved from http://opinion.inquirer.net/91905/easing-manila-traffic-congestion (10 May 2016).

Santos, M. L. M. (2013). Western Texts and New Worlds: Politics of Identity in a Philippine Fan Community. Philippine Humanities Review, 15(1), 51-67.

Shirky, C. (2011). Cognitive Surplus: How Technology Makes Consumers into Collaborators. New York: Penguin Books. . (2008). Here Comes Everybody: The Power of Organizing without Organizations. London: Allen Lane.

Taxikick.com. (n.d.). Taxikick / Help. Retrieved from http://www.taxikick.com/help, (11 May 2016).

Tedre, M., et al. (2006). Ethnocomputing: ICT in Cultural and Social Context. Communications of the ACM, 49, 126-130. 
Thorne, S. L., et al. (2009). Second Language Use, Socialization, and Learning in Internet Interest Communities and Online Gaming. The Modern Language Journal, 93, 802-821. doi:0026-7902/09/802-821

World Bank Indicators. Internet Users (per 100 People). Retrieved from http://data.worldbank.org/indicator/IT.NET.USER.P2 (10 May 2016).

. (2016). Agenda of the Next President: Traffic. Philippine Daily Inquirer, 16 February 2016. Retrieved from http://newsinfo.inquirer.net/764749/elections-2016-agenda-next-presidenttraffic-voteph2016 (10 May 2016). (2016a). READ: Complete Transcript of Final Presidential Debate. Philippine Daily Inquirer, 25 April 2016. Retrieved from http://newsinfo.inquirer.net/781485/read-complete-transcript-of-finalpresidential-debate (10 May 2016). . (2015). Philippines: Manila Voted Worst City to Drive on Earth, $B B C$ online, 02 October 2015. Retrieved from http://www.bbc.com/news/blogsnews-from-elsewhere-34424367 (11 May 2016). 